\title{
Complementary Catalytic Strategies to Access $\alpha$-Chiral Aldehydes
}

\author{
Clément Mazet
}

Werner Prize Winner 2013

\begin{abstract}
The present article summarizes the development of two novel and complementary catalytic methods to access $\alpha$-chiral aldehydes. A $C_{1}$-symmetric chiral $(P, N)$ ligand with a structure derived from the ubiquitous binepine scaffold has been specifically designed for the Pd-catalyzed $\alpha$-arylation of aldehydes to access indane derivatives with a well-defined quaternary stereocenter in high yields and excellent enantioselectivities. In addition, a dinuclear palladium hydride catalyst has been synthesized for the isomerization of terminal and trisubstituted epoxides into aldehydes and ketones respectively. Combined experimental and theoretical investigations pointed to an unprecedented 'epoxide-opening/hydride-transfer' sequence. The mechanism also features two distinct enantio-determining steps in the kinetic resolution of racemic epoxides.
\end{abstract}

Keywords: Aldehydes · Catalysis · Cross-coupling · Isomerization · Palladium

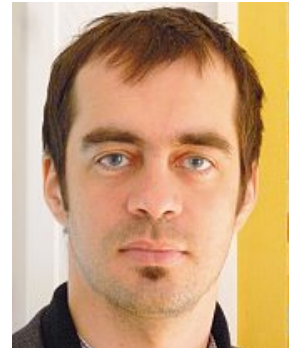

After two years undergraduate studies in the laboratory of the late Professor John A. Osborn at the University of Strasbourg (France), Clément Mazet carried out his $\mathrm{PhD}$ research work under the guidance of Professor Lutz H. Gade in the same University. In 2003, he moved to Basel (Switzerland) where he worked as a postdoctoral fellow in the group of Professor Andreas Pfaltz. In 2006 he was awarded a Marie Curie International Outgoing Fellowship and spent nearly two years working with Professor Eric N. Jacobsen at Harvard University (MA, USA).

$\mathrm{He}$ joined the Organic Chemistry Department of the University of Geneva in November 2007 to build up his independent research group as a Maittre Assistant. In 2011, he was awarded a prestigious Swiss National Foundation Professorship (SNF Professorship). His research interests include mechanistic and synthetic chemis- try with particular emphasis on asymmetric catalysis. He recently received the $1^{\text {st }}$ Zasshikai Lectureship from the University of Tokyo (2012) and the Werner Prize from the Swiss Chemical Society (2013) in recognition of his work in asymmetric catalysis.

\section{Introduction}

Among other research activities, a large part of our program is currently aimed at developing innovative and complementary catalytic methods using well-defined organometallic complexes to access chiral aldehydes. Our initial motivation stems from the high prevalence of aldehydes as essential building blocks in synthesis and/ or as a key function in biologically active compounds. Although aldehydes are usually associated with food additives and important fragrances, they are also often found as pivotal intermediates in the synthesis of complex molecular architectures with applications in medicinal, pharmaceutical or even material sciences. ${ }^{[1]}$ On the other hand, the versatile reactivity of the aldehyde functionality is intimately associated with its relative instability. Hence, at the outset of our investigations, we postulated that devising catalytic methods that would be tolerant to this peculiar oxidation state of the carbon atom may, in turn, be highly functional group tolerant as they would be compatible with more robust functional groups. Embarking in this direction we also anticipated that we will certainly be confronted with more fundamental mechanistic questions that might be worth deciphering using the most recent practical and theoretical tools of the physical-organic chemist.

Previous methods developed in our group to access chiral aldehydes include the iridium-catalyzed isomerization of primary allylic alcohols ( $\beta$-chiral aldehydes), ${ }^{[2]}$ the sequential iridium/enamine catalysis using the same substrates and diverse electrophiles $(\alpha, \beta \text {-chiral aldehydes })^{[3]}$ and the iridium catalyzed-hydroboration of terminal $\alpha$-olefins followed by successive oxidations ( $\alpha$-chiral aldehydes). ${ }^{[4]}$ These have already been discussed in a previous issue of this journal. ${ }^{[5]}$ In the present article, we summarize the development of two additional and complementary methods that were specifically devised to gain access to $\alpha$-chiral aldehydes possessing either a tertiary or a quaternary (stereo)center.

\section{Pd-Catalyzed $\alpha$-Arylation of Aldehydes}

The palladium-catalyzed enantioselective $\alpha$-arylation of carbonyl compounds has advanced at an impressive pace since the seminal report from Musco and Santi in 1992. [6] Challenges in this field are threefold. ${ }^{[7]}$

i) Tertiary $\alpha$-chiral carbonyls obtained from linear substrates tend to rapidly epimerize under the necessary basic conditions. Advances in this direction have recently appeared in the literature for the $\alpha$-arylation of pre-activated esters under mildly basic reaction conditions, though ample room remains for further improvements. ${ }^{[8]}$ 
ii) $\alpha$-Branched substrates are not confronted with the issue of post-reaction epimerization but instead face the inherent difficulties associated with forging quaternary stereocenters. ${ }^{[9]}$

iii) The nature of the carbonyl compounds imparts an additional challenge directly related to the reactivity and stability of the $\mathrm{C}=\mathrm{O}$ double bond. Hence, not surprisingly, examples of asymmetric $\alpha$-arylation of amides or esters are numerous whereas ketones have been much less employed.[10] More importantly, at the beginning of our investigations, a single example of $\mathrm{Pd}$-catalyzed asymmetric $\alpha$-arylation of $\alpha$-branched aldehydes had been reported. ${ }^{[1]}$ In addition to the sensitivity of the aldehyde functionality, the basic conditions required for cross-coupling may favor numerous undesired sidereactions such as self-aldol condensations, Cannizzaro or Tishchenko disproportionations..$^{[7,12]}$ Furthermore, from a stereoselective point of view, aldehydes are more
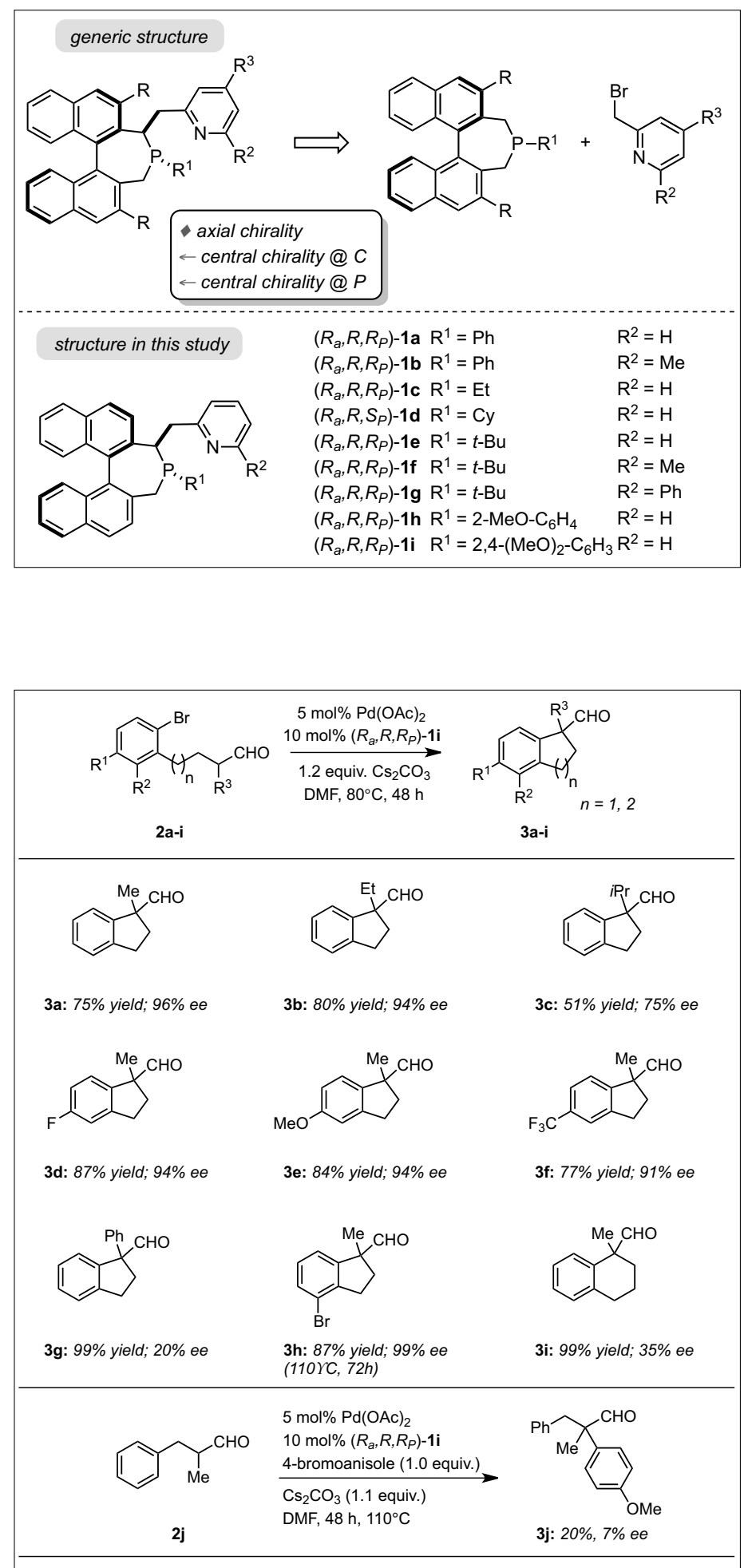

difficult substrates as they lack a large vicinal substituent ( $-\mathrm{H}$ vs. $-\mathrm{R},-\mathrm{OR}$ or $-\mathrm{N}\left(\mathrm{R}^{1}\right)$ $\mathrm{R}^{2}$ ) that may constructively interact with the chiral catalyst during the enantioselection process.

The generic structure of the chiral $(\mathrm{P}, \mathrm{N})$ ligand we designed for the $\alpha$-arylation of aldehydes is presented in Scheme 1. ${ }^{[13]}$ It distinguishes itself by a highly modular scaffold possessing three elements of chirality: i) the axial chirality of the elementary binepine core; ${ }^{[14]}$ ii) a central chirality at a benzylic position; iii) a phosphorus stereogenic center. The latter two elements are stereoselectively installed by introduction of the methylpyridyl unit according to a strategy already employed by Wildhalm and Zhang. ${ }^{[15]}$ Nine different ligands were initially synthesized in acceptable to good overall yields. Substituents with various steric and electronic demands were introduced at the phosphorus atom and the ortho position of the pyridyl ring.

Optimizations of the reaction conditions ( 1.2 equiv. $\mathrm{Cs}_{2} \mathrm{CO}_{3}, 80^{\circ} \mathrm{C}, \mathrm{DMF}, 48 \mathrm{~h}$ ) were performed using 4-(2-bromophenyl)2-methylbutanal $\mathbf{2 a}$ as a model substrate and ligand $\left(R_{q}, R, R_{p}\right)$-1e (75\% yield, $96 \%$ ee) (Scheme 2, top). While bromoarenes underwent cyclization, aryl chlorides and iodides failed to react. Evaluation of all other members of this new ligand class indicated that $\left(R_{q}, R, R_{p}\right)$-1i was clearly outstanding in terms of reactivity and selectivity. With this candidate, a variety of indane derivatives was obtained in consistently high yield and enantioselectivity (9 examples, 51-99\% yield, 35-99\% ee). Primary alkyl $\alpha$-substituents were well tolerated whereas secondary alkyls had a detrimental effect on both the reactivity and the selectivity. The system proved insensitive to variations of the electronic properties of the bromoarenes moiety. More interestingly, the use of a dibrominated substrate $\mathbf{2 h}$ resulted in product formation in excellent yield and nearly perfect enantioselectivity ( $87 \%$ yield, $99 \% e e$ ) and, remarkably, the second bromine atom remained intact in the cyclized product. This observation is consistent with reversible oxidative addition of $\operatorname{Pd}(0)$ intermediates into the carbon-halogen bond and was further substantiated by engaging the product in other $\mathrm{C}-\mathrm{C}$ bond forming processes using various electrophiles under otherwise identical reaction conditions. Such an observation is rare in Pd-catalyzed cross-coupling reactions and had not been documented in the context of asymmetric catalysis..[16]

A real breakthrough in the enantioselective $\alpha$-arylation of carbonyl compounds would consist in developing intermolecular variants of these transformations. ${ }^{[17]}$ Preliminary results obtained with $\left(R, R, R_{p}\right)$-1i in the cross-coupling between 2-methyl-3-phenylpropanal and 4-bro- 
moanisole further highlight the difficulty associated with this task (Scheme 2, bottom).

\section{Isomerization of Terminal Epoxides}

As emphasized above, the enantioselective $\alpha$-arylation of linear carbonyl derivatives in general and of aldehydes in particular remains a formidable challenge. Although work in this direction is currently on-going in our laboratory, we have also tackled this issue from a rather different angle. ${ }^{[18]}$

We identified the isomerization of terminal epoxides (Scheme 3 ) as a potentially very attractive alternative method to access $\alpha$-chiral aldehydes with a tertiary stereocenter. In principle, starting from readily accessible substrates, the isomerization of epoxides enables direct access to the corresponding carbonyl derivatives. Despite its occasional implementation in synthesis, this reaction suffers from several limitations. ${ }^{[19]}$ Super-stoichiometric amounts of reagents rather than well-defined catalysts, unpredictable reaction outcome, plethora of side-reactions, high substrate specificity and an ill-defined mechanistic picture have prevented widespread use of this method. Examples of stereospecific isomerizations of epoxides are very rare and have been described only for trisubstituted epoxides. ${ }^{20]}$ Furthermore, although the kinetic resolution of racemic 2,3-disubstituted and trisubstituted epoxides has been documented, the main focus was to access either enantioenriched epoxides or enantioenriched allylic alcohols. In spite of the aforementioned shortcomings, we initially set out to develop an asymmetric version of this transformation to access enantioenriched $\alpha$-chiral aldehydes.

Our approach was inspired by the contribution of Bunel and co-workers who had described the use of well-defined $\mathrm{Pd}-\mathrm{H}$ catalysts for the related isomerization of terminal olefins. ${ }^{[21]}$ More importantly, Kulawiec and co-workers had also reported the highly selective isomerization of 2-methyl-2-(2-naphthyl)-oxirane with a combination of $\mathrm{Pd}(\mathrm{OAC})_{2}$ and $\mathrm{PPh}_{3} \cdot{ }^{[22]}$ This precedent constituted a rare example of a catalytic isomerization of terminal epoxides, though it turned out to proceed exclusively for this substrate and required the use of a protic solvent - a detrimental parameter in view of developing an asymmetric version of this reaction as it favors rapid enolization.

During re-optimization of the conditions initially reported by Kulawiec to develop a widely applicable protocol, we identified a novel dinuclear $\mathrm{Pd}-\mathrm{H}$ complex 4 which proved competent in the selective

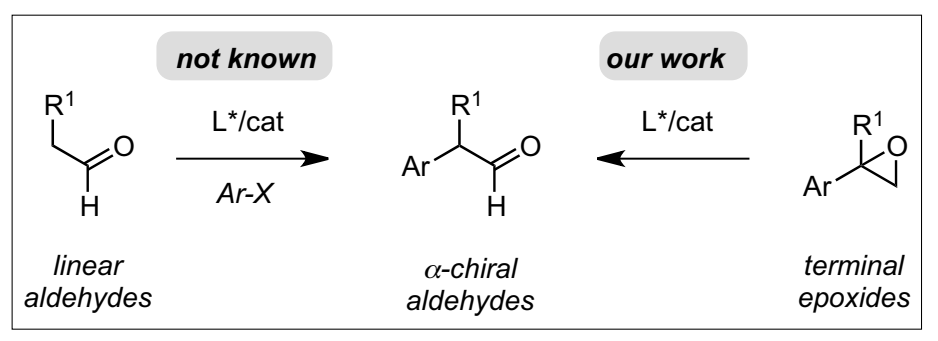

Scheme 3.

Complementary strategies to access $\alpha$-chiral aldehydes.

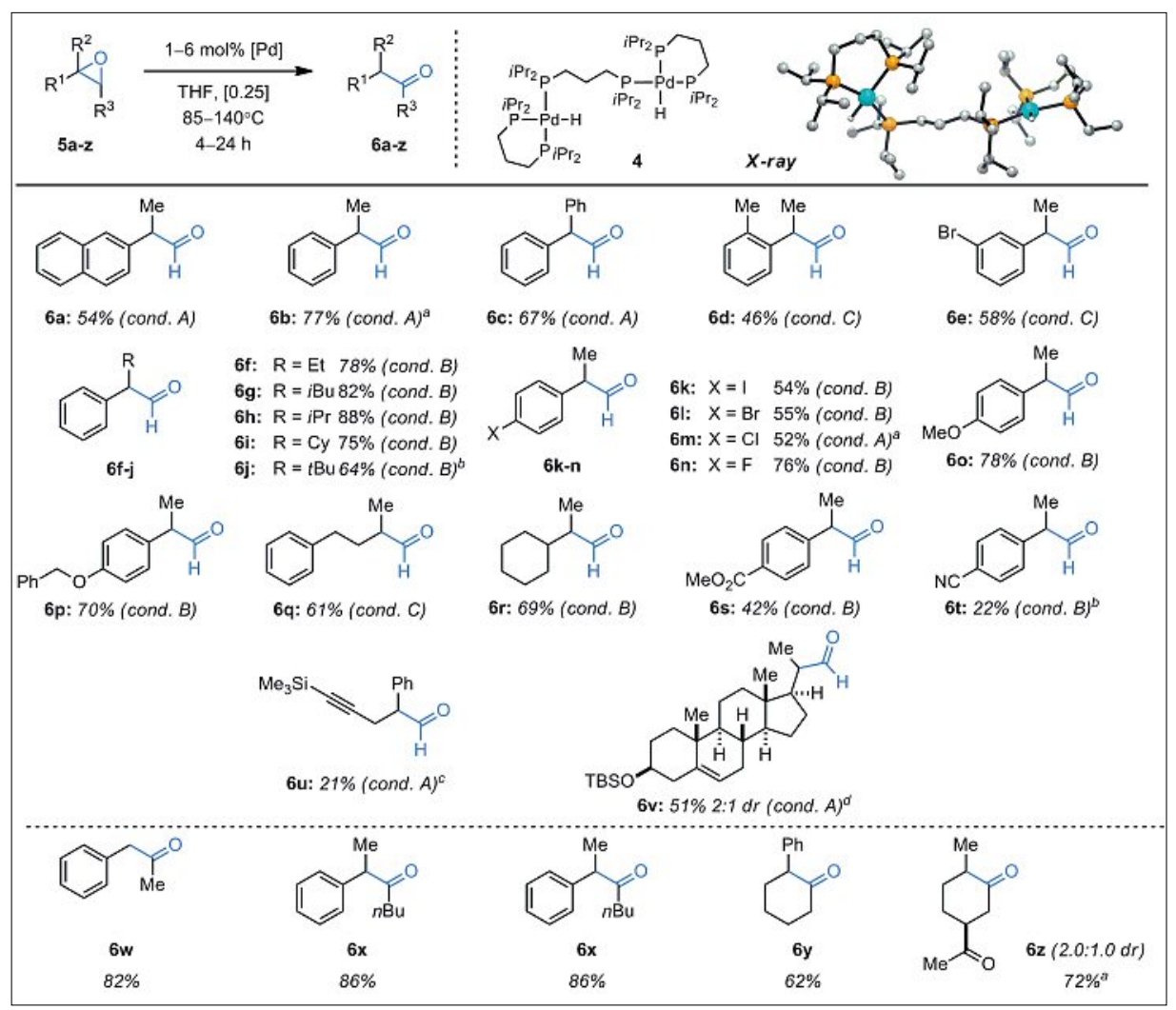

Scheme 4. Scope for the $[\mathrm{Pd}-\mathrm{H}]$-catalyzed isomerization of terminal and trisubstituted epoxides.

isomerization of terminal and trisubstituted epoxides into aldehydes and ketones respectively (1-6 mol\% [Pd], THF, $85-140^{\circ} \mathrm{C}, 4-24 \mathrm{~h}$ ). The functional group tolerance of the method was delineated and aryl halides $(\mathbf{6 k - n})$, alkoxy groups $(\mathbf{6 o}, \mathbf{p})$ ester $(\mathbf{6 s})$, cyano (6t), alkynes (6u), alkenes $(\mathbf{6 v})$, as well as ketones $(\mathbf{6 z})$ were all tolerated and the corresponding products were isolated in practical to excellent yields (Scheme 4). Although the method was initially designed as an alternative to the $\alpha$-arylation of linear aldehydes, substrates containing two alkyl substituents in the $\alpha$-position were also isomerized efficiently $(6 \mathbf{q}, 6 \mathbf{r}, 6 \mathbf{v}, 6 \mathbf{z})$.

A series of experimental investigations - which were further corroborated by DFT calculations - pointed to an unprecedented hydride-type mechanism (Scheme 5). Preliminary results obtained in the kinetic resolution of terminal epoxides (stereodivergent) and in the isomerization of enantioenriched 2-methyl-2-phenyloxirane (94\% ee) into racemic 2-phenylpropanal (stereoconvergent) revealed that two distinct enantio-determining steps were oper- ating in sequence. A pathway that accounts for partial racemization of the enantio-enriched aldehyde in presence of the $\mathrm{Pd}-\mathrm{H}$ catalyst and that lies off the productive catalytic cycle was also identified.

Although far from practicality, the preliminary results obtained using commercially available chiral bisphosphine ligands clearly set a precedent that will serve as a stepping-stone for further developments of a more efficient asymmetric isomerization of terminal epoxides to access chiral aldehydes with a $\alpha$-tertiary stereocenter.

\section{Conclusions}

The present article summarizes the development of two novel and complementary catalytic methods to access $\alpha$-chiral aldehydes. A novel $C_{1}$-symmetric chiral $(\mathrm{P}, \mathrm{N})$ ligand with an original structure derived from the ubiquitous binepine scaffold has been specifically designed for the Pd-catalyzed $\alpha$-arylation of aldehydes. This reaction generates indane derivatives with a well-defined quaternary stereocen- 


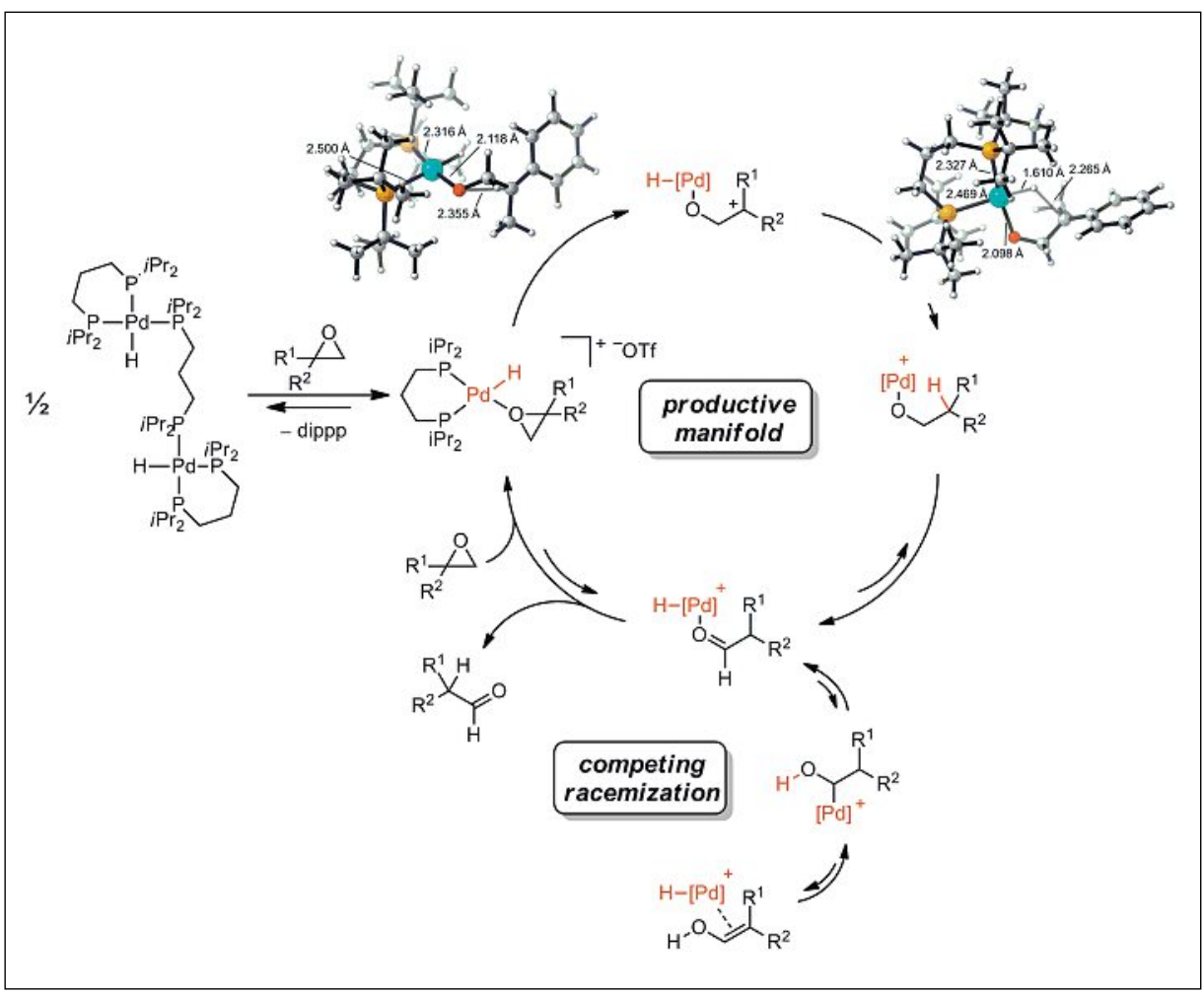

Scheme 5. Proposed catalytic cycle for the $[\mathrm{Pd}-\mathrm{H}]$-catalyzed isomerization of terminal epoxides. The molecular structures are calculated transition states for the two key elementary steps (DFT method: B3LYP/[LANL2DZ on Pd, 6-31G(d) on H, C, O, P], PCM in THF at the same level using dtbpp (1,3-bis(di-tert-butylphosphino)propane) as a model ligand). See ref. [18] for further details.

ter. High yields and excellent enantioselectivities have been obtained for the intramolecular variant of this transformation. A reversible oxidative addition of $\operatorname{Pd}(0)$ into aryl-bromine bond was also observed. To complement this strategy, a unique dinuclear palladium hydride catalyst has been synthesized for the isomerization of terminal and trisubstituted epoxides into aldehydes and ketones respectively. Combined experimental and theoretical investigations pointed to an unprecedented 'epoxide-opening/hydride-transfer' mechanistic sequence. Preliminary observations also revealed that two distinct enantio-determining steps were operating consecutively for the kinetic resolution of racemic epoxides. A pathway that accounts for partial racemization of the enantio-enriched aldehyde and that lies off the productive catalytic cycle was also identified. These results clearly set a precedent for further developments of a more practical asymmetric isomerization of terminal epoxides. Current efforts are directed toward improving the efficiency of these catalytic processes to access synthetically valuable $\alpha$-chiral aldehydes.

\section{Acknowledgements}

The results summarized in this article have been carried out by a group of talented and highly dedicated co-workers to whom I am deeply indebted. Their names appear in the list of references below. The author also thanks the University of Geneva, the Swiss National
Science Foundation, the Société Académique de Genève and Roche for financial support. Johnson-Matthey, Solvias and BASF are equally acknowledged for generous gifts of chemicals.

Received: July 14, 2013

[1] D. Evans in 'Asymmetric Synthesis', Vol. 1, Ed. J. D. Morrison, Academic Press: New York, 1984; b) D. Seebach, R. Imwinkelried, T. Weber in 'Modern Synthetic Methods' Ed. R. Scheffold, Springer: Berlin, 1986; c) 'Molecules and Medicine'. Eds. E. J. Corey, B. Czakó, L. Kürti, John Wiley \& Sons, Inc., Hoboken, New Jersey, 2007.

[2] a) L. Mantilli, C. Mazet, Tetrahedron Lett. 2009, 50, 4141; b) L. Mantilli, D. Gérard, S. Torche, C. Besnard, C. Mazet, Angew. Chem. Int. Ed. 2009, 48, 5413; c) L. Mantilli, C. Mazet, Chem. Commun. 2010, 46, 445; d) L. Mantilli, D. Gérard, S. Torche, C. Besnard, C. Mazet, Chem. Eur. J. 2010, 16, 12736; e) L. Mantilli, D. Gérard, C. Besnard, C. Mazet, Eur. J. Org. Chem. 2012, 20, 3320.

[3] A. Quintard, A. Alexakis, C. Mazet, Angew. Chem. Int. Ed. 2011, 50, 2354

[4] C. Mazet, D. Gérard, Chem. Commun. 2011, 40, 341.

[5] C. Mazet, Chimia 2011, 65, 802.

[6] R. Galarini, A. Musco, R. Pontellini, R. Santi, J. Mol. Cat. 1992, 72, L11.

[7] a) D. A. Culkin, J. F. Hartwig, Acc. Chem. Res. 2003, 36, 234; b) A. C. B. Bortoloso, Synlett $2009,2,320$; c) C. C. C. Johansson, T. J. Colacot, Angew. Chem. Int. Ed. 2010, 49, 676; d) F. Bellina, R. Rossi, Chem. Rev. 2010, 110, 1082; e) C. Mazet, Synlett 2012, 23, 1999.

[8] a) Z. Huang, Z. Liu, J. Zhou, J. Am. Chem. Soc. 2011, 133, 15882; b) K. Kobayashi, Y. Yamamoto, N. Miyaura, Organometallics 2011 30, 6323; c) Z. Huang, L. Hui Lim, Z. Chen, Y.
Li, F. Zhou, H. Su, J. Zhou, Angew. Chem. Int. Ed. 2013, 52, 4906.

[9] a) 'Quaternary Stereocentres: Challenges and Solutions for Organic Synthesis', Eds. J. Christoffers, A. Baro, Wiley-VCH: Weinheim, 2005; b) K. Fuji, Chem. Rev. 1993, 93, 2037; c) A. B. Dounay, L. E. Overman, Chem. Rev. 2003, 103, 2945; d) M. Bella, T. Gasperi, Synlett, 2009, 10, 1583; e) I. Marek, G. Sklute, Chem. Commun. 2007, 1683; f) C. Hawner, A. Alexakis, Chem. Commun. 2010, 46, 7295.

[10] For the $\alpha$-arylation of amides, see: a) S. Lee, J. F. Hartwig, J. Org. Chem. 2001, 66, 3402; b) T. Aaro, K. Kondo, T. Aoyama, Tetrahedron Lett. 2006, 47, 1417; c) E. P. Kündig, T. M. Seidel, Y.-X. Jia, G. Bernardinelli, Angew. Chem. Int. Ed. 2007, 46, 8484; d) X. Luan, R. Mariz, C. Robert, M. Gatti, S. Blumentritt, A. Linden, R. Dorta, Org. Lett. 2008, 10, 5569; e) S. Würtz, C. Lohre, R. Fröhlich, K. Bergander, F. Glorius, J. Am. Chem. Soc. 2009, 131, 8344; f) X. Luan, L. Wu, E. Drinkel, R. Mariz, M. Gatti, R. Dorta, Org. Lett. 2010, 12, 1912; g) Y.-X. Jia, D. Katayev, G. Bernardinelli, T. M. Seidel, E. P. Kündig, Chem. Eur. J. 2010, 16, 6300; h) L. Liu, N. Ishida, S. Ashida, M. Murakami, Org. Lett. 2011, 13, 1666. For relevant examples on the $\alpha$-arylation of esters, see: i) D. J. Spielvogel, S. L. Buchwald, J. Am. Chem. Soc. 2002, 124, 3500; j) D. J. Spielvogel, W. M. Davis, S. L. Buchwald, J. Am. Chem. Soc. 2002, 121, 3833; k) X. Liu, J. F. Hartwig, J. Am. Chem. Soc. 2004, 126, 5182. For diastereoselective reactions: 1) E. A. Bercot, S. Caille, T. M. Bostick, K. Ranganathan, R. Jensen, M. M. Faul, Org. Lett. 2008, 10, 5251; m) L. Jiang, S. Weist, S. Jansat, Org. Lett. 2009, 11, 1543. For relevant examples on the $\alpha$-arylation of ketones, see: $n$ ) T. Satoh, Y. Kawamura, M. Miura, M. Nomura, Angew. Chem. Int. Ed. 1997, 36, 1740; o) Y. Terao, T. Satoh, M. Miura, M. Nomura, Bull. Chem. Soc. Jpn. 1999, 72, 2345; p) M. Palucki, S. L. Buchwald, J. Am. Chem. Soc. 1997, 119, $11108 ;$ q) B. C. Hamann, J. F. Hartwig J. Am. Chem. Soc. 1997, 119, 12382; r) M. S. Viciu, R. F. Germaneau, S. P. Nolan, Org. Lett. 2002, 4, 4053; s) V. Lavallo, Y. Canac, C. Präsang, B. Donnadieu, G. Bertrand, Angew. Chem. Int. Ed. 2005, 44, 5705; t) G. A. Grasa, T. J. Colacot, Org. Lett. 2007, 9, 5489; u) T. J. Colacot, H. A. Shea, Org. Lett. 2004, 6, 3731; v) C. Richter, K. V. S. Ranganath, F. Glorius, Adv. Synth. Catal. 2012, 354, 377.

[11] J. García-Fortanet, S. L. Buchwald, Angew. Chem. Int. Ed. 2008, 47, 8108 .

[12] P. Nareddy, C. Mazet, Chem. Asian J. 2013, in press.

[13] a) P. Nareddy, L. Mantilli, L. Guénée, C. Mazet, Angew. Chem. Int. Ed. 2012, 51, 3826; b) N. Humbert, E. Larionov, L. Mantilli, P. Nareddy, C. Besnard, L. Guénée, C. Mazet, submitted.

[14] S. Gladiali, E. Alberico, K. Junge, M. Beller, Chem. Soc. Rev. 2011, 40, 3744.

[15] a) P. Kasák, K. Mereiter, M. Wildhalm, Tetrahedron: Asym. 2005, 16, 3416; b) P. Kasák, V. B. Arion, M. Widhalm, Tetrahedron: Asym. 2006, 17, 3084; c) Q. Dai, W. Li, X. Zhang, Tetrahedron 2008, 64, 6943.

[16] a) A. H. Roy, J. F. Hartwig, J. Am Chem. Soc. 2001, 123, 1232; b) A. H. Roy, J. F. Hartwig, J. Am Chem. Soc. 2003, 125, 13944; c) S. G. Newman, M. Lautens, J. Am. Chem. Soc. 2010, $132,11416$.

[17] A single intermolecular asymmetric $\alpha$-arylation of carbonyl compounds/amides has been reported to date: A. M. Taylor, R. A. Altman, S. L. Buchwald, J. Am. Chem. Soc. 2009, 131, 9900.

[18] D. J. Vyas, E. Larionov, C. Besnard, L. Guénée, C. Mazet J. Am. Chem. Soc. 2013, 135, 6177. 
[19] For reviews, see: a) K. A. Jørgensen, B. Schiøtt, Chem. Rev. 1990, 90, 1483; b) L. F. Silva Jr., Tetrahedron 2002, 58, 9137. For applications in synthesis, see: c) T. Bando, K. Shishido, Chem. Commun. 1996, 1357; d) M. Matsushita, H. Maeda, M. Kodama, Tetrahedron Lett. 1998, 39, 3749; e) T. Kinura, N. Yamamoto, Y. Suzuki, K. Kawano, Y. Norimine, K. Ito, S. Nagato, Y. limura, M. Yonaga, J. Org. Chem. 2002, 67, 6228. For seminal contributions, see: f) H. O. House, J. Am. Chem. Soc. 1954, 77, 3070; g) S. M. Naqvi, J. P. Horowitz, R. Filler, J. Am. Chem. Soc. 1957, 79, 6283; h) J. Meinwald, S. S. Labana, M. S. Chadha, J. Am. Chem. Soc. 1962, 85, 582 .

[20] a) K. Maruoka, T. Ooi, H. Yamamoto, J. Am. Chem. Soc. 1989, 111, 6431; b) K. Suda, T. Kikkawa, S.-i. Nakajima, T. Takanami, J. Am. Chem. Soc. 2004, 126, 9554; c) K. Suda, S.i. Nakajima, Y. Satoh, T. Takanami, Chem. Commun. 2009, 1255; d) R. Hrdina, C. E. Müller, R. C. Wende, K. M. Lippert, M.Benassi, B. Spengler, P. R. Schreiner, J. Am. Chem. Soc. 2011, 133, 7624; e) F. Peng, S. J. Danishefski, J. Am. Chem. Soc. 2012, 134, 18860.

[21] P. J. Perez, J. C. Calabrese, E. E. Bunel, Organometallics 2001, 20, 3161.

[22] a) S. Kulasegaram, R. J. Kulawiec, J. Org. Chem. 1994, 59, 7195; b) J.-H. Kim, R. J. Kulawiec, J. Org. Chem. 1996, 61, 7656; c) S. Kulasegaram, R. J. Kulawiec, J. Org. Chem. 1997, 62, 6547; d) S. Kulasegaram, R. J. Kulawiec, Tetrahedron 1998, 54, 1361. 